\title{
Effect of the Non-monotonic Dependence of the Water Density on Temperature on Convection Induced by Cooling from above
}

\author{
Victor Ivanovich Bukreev \\ Lavrentyev' Institute of Hydrodynamics, Siberian Branch of Russian Academy of Sciences \\ 15 Lavrentyev' av., Novosibirsk, 630090, Russia \\ E-mail: bukreev@hydro.nsc.ru
}

Received: October 17, 2012 Accepted: November 5, 2012 Published: January 1, 2013

doi:10.5296/ast.v1i1.2724 URL: http://dx.doi.org/10.5296/ast.v1i1.2724

\begin{abstract}
Temperature distributions on the depth typical for deep lakes of middle latitudes were reproduced in the laboratory conditions. In these lakes, a thick bottom layer of water with an invariable temperature exists regardless of season. It is shown that the non-monotonic dependence of the density of water on temperature plays determining role in the existence of such distributions. Flow patterns obtained by visualization and quantitative data on changes of the water temperature in time and space are presented.
\end{abstract}

Keywords: Convection, Deep lakes, Thermal regime, Steady bottom layer 


\section{Introduction}

The temperature dependence of the fresh water density is nonlinear and non-monotonic. At atmospheric pressure, distilled water has the maximal density at the temperature $T_{*} \approx 4{ }^{\circ} \mathrm{C}$. When fresh water masses with temperatures lower and higher than $T_{*}$ are mixed each other some portion of the mixture acquires the maximal density and becomes heavier than surrounding water. It results in convective instability which plays an important role in ecology of fresh-water reservoirs. For example, the thermal bar, i.e. a vertical front separating water masses with temperatures higher and lower than $4{ }^{\circ} \mathrm{C}$, is formed in spring and autumn in fresh and low saline reservoirs of middle latitudes. The thermal bar plays the key role in the exchange of oxygen and nutrients throughout the reservoir. The thermal bar was firstly described by Forel (1904). A review of a great number of studies of the thermal bar can be found in the works (Imberger \& Hamblin, 1982; Tichomirov, 1983; Zilitinkevch et al., 1992; Holland \& Kay, 2003). Laboratory studies of the thermal bar were carried out in the works (Chubarenko \& Demchenko, 2008; Bukreev \& Gavrilov, 2010). The plunging phenomenon is essential for the exchange of oxygen and nutrients (Singh \& Shah, 1971). The plunging of a fresh water jet with a temperature higher than $4{ }^{\circ} \mathrm{C}$ flowing to the fresh water with a temperature lower than $4{ }^{\circ} \mathrm{C}$ was studied in the experiments (Bukreev, 2011).

The anomalous temperature dependence of the water density plays an important role in the existence of a long-term thermal regime of deep reservoirs of middle latitudes. For example, in the near-bottom zone of Lake Baikal, there is a thick layer where a temperature of water remains unchangeable and equals to $(3.2 \div 3.6){ }^{\circ} \mathrm{C}$ independently of seasonal and long-term temperature changes in a surface layer (Shimarayev, 1977). It is essential that some heat constantly comes into deep lakes from the bottom. The geothermal gradient in earth materials in flat lands is approximately equal to $30{ }^{\circ} \mathrm{C}$ per kilometer of the depth. The depth of Lake Baikal is about $1.6 \mathrm{~km}$. In this lake, the free surface has the altitude equaled $700 \mathrm{~m}$ above sea level so a temperature of rocks under the lake bottom is not less than $30^{\circ} \mathrm{C}$.

Some valuable information about the formation mechanism of a steady layer of cold water surrounded by warmer water was obtained in the laboratory experiments (Townsend, 1964; Adrian, 1975). In these experiments, water was cooled from below by ice located at the bottom. Such situation is typical for some Alpine lakes freezing down to the bottom. As a rule, deep lakes are not frozen down to the bottom. In summer, heat arrives into them both from above and below.

The present work gives some results of laboratory experiments in which heat was taken out from a closed rectangular tank with the fresh water through a tank cover only and the same quantity of heat arrived to the tank through its bottom and all side walls. Heat fluxes were relatively weak. This made it possible to obtain a steady bottom layer with a temperature about $4{ }^{\circ} \mathrm{C}$.

\section{Experimental Technique}

Figure 1(a) presents the scheme of the experiment. The rectangular tank with the length of $27.2 \mathrm{~cm}$, the width of $15.5 \mathrm{~cm}$ and the height of $22 \mathrm{~cm}$ was used (the inner dimensions are specified). The tank walls of $0.4 \mathrm{~cm}$ in thickness were glass. The tank was located in a room with the temperature $T_{\infty}=19.5 \pm 0.5{ }^{\circ} \mathrm{C}$. During the experiments lasting up to 16 hours, the 


\section{Macrothink

value $T_{\infty}$ changed by no more than $\pm 0.3{ }^{\circ} \mathrm{C}$. The tank was mounted on supports of $4 \mathrm{~cm}$ in height so not only the side walls but also the bottom were in the direct contact with air. The tank was filled with tap water with the temperature range $0.2 \leq T_{0} \leq 10{ }^{\circ} \mathrm{C}$. Salinity of this water was about $300 \mathrm{mg} / \mathrm{l}$. The density of water with salinity of $300 \mathrm{mg} / \mathrm{l}$ in the considered range of temperatures is greater than that of the distilled water by $0.0013 \%$. It is approximately in 10 times less than the difference of the densities of the distilled water at 4 ${ }^{\circ} \mathrm{C}$ and at $0{ }^{\circ} \mathrm{C}$. It should be noted for comparison that salinity in Lake Baikal is equal to 96 $\mathrm{mg} / \mathrm{l}$ (Shimarayev, 1977).

(a)

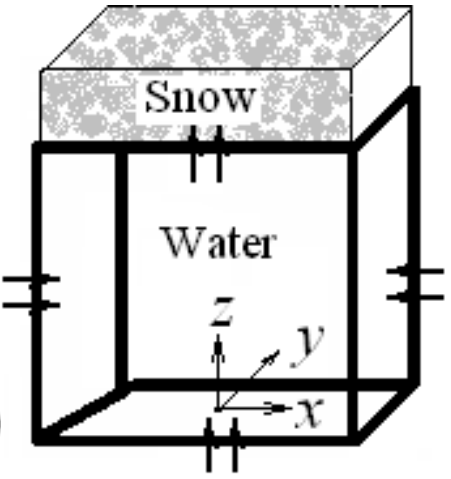

Figure 1(a). Diagram of the experiment

(b)

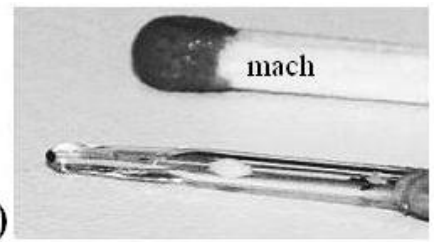

(c)

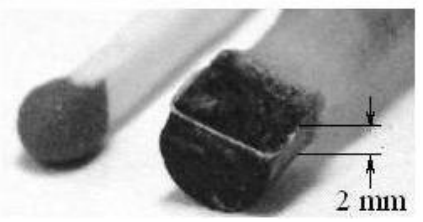

Figure 1(b). Thermistor sensors

The experiment started with closing the tank with water by the washtub-like cover adjoining closely to water and to the vertical walls of the tank. The washtub was made of the galvanized iron of $0.05 \mathrm{~cm}$ in thickness. The washtub was filled and periodically supplemented with snow. A melted water layer with the temperature of $0{ }^{\circ} \mathrm{C}$ existed at the bottom of the washtub during the whole experiment. The excess amount of the melted water was released through the hole whose the lower edge was at the height of $2.5 \mathrm{~cm}$ from the washtub bottom. The temperature of the washtub lower surface, which was in contact with water, was equal to $0.1{ }^{\circ} \mathrm{C}$.

Temperature was measured by thermistor sensors of two types (see Figure 1). The sensing element of the sensor of one type (a thermistor covered by the glass, Figure 1(b)) has the sphere form with diameter of $0.25 \mathrm{~cm}$. Such sensors were used to measure temperatures in 
different points inside the tank including those at the distance of $0.125 \mathrm{~cm}$ from the inner surfaces of the tank walls. The sensing element of the sensor of the second type (Figure 1(c)) has the form of a parallelepiped with the height of $0.2 \mathrm{~cm}$ and the square base of $0.4 \mathrm{~cm}^{2}$. These sensors were fixed by their bases on the inner and outer surfaces of the tank walls.

Calibration of the temperature sensors was carried out through each 2-3 experiments. The signals of the sensors were registered by a computer with pauses of 3-5 minutes at the initial stage of measurements and of 15-30 minutes at the stage of slow changes of the studied processes. The record duration between the pauses was equal to 20-30 sec. The mean-square value of the random error of measurements, conditioned mostly by the electronic noise of the measuring system, did not exceed $0.02{ }^{\circ} \mathrm{C}$.

Visualization of water motions in the tank was carried out. Optical methods are widely used for this aim. Optical methods are effective at initial stages of heat-exchange process when density gradients are large enough. In the present work, the steady state of the heat exchange was of special interest. Density gradients in this stage were too small to use optical methods. Therefore, visualization was performed by using weak water solutions of ink, or potassium permanganate, or uranine (see http://en.wikipedia.org/wiki/Fluorescein).

\section{Some Experimental Results}

The initial temperature of water in the tank was lower than that of air in the room in all experiments. The process of heat exchange of air and water was at first unsteady. If the initial water temperature was lower than $4{ }^{\circ} \mathrm{C}$, the heat amount supplied through the glass walls exceeded firstly the heat amount abstracted into the washtub where heat was generally spent for the phase transition of snow into water. If the initial water temperature was higher than 4 ${ }^{\circ} \mathrm{C}$, the amount of the supplied heat was firstly less than the amount of the abstracted heat. After a while, a steady state was formed when the amounts of the supplied and abstracted heat became equal each other.

Thin dynamic and thermal boundary layers were formed on the outer and inner surfaces of the tank glass walls. Thermal and dynamic boundary layers were also formed on the cover. In the steady state, the greatest temperature difference between air and water out of the boundary layers was about $15{ }^{\circ} \mathrm{C}$. The temperature drop in the air boundary layers was about $75 \%$ of the summary drop; in the glass walls it was about $15 \%$ and in the water boundary layers it was only $10 \%$ from the summary drop. In the boundary layers on the outer surfaces of the glass walls, air was colder and heavier than air in the room and its flow was directed downwards. In the boundary layers on the inner surfaces of the tank side walls, heated water rose and collected near the cover.

Convective instability took place both near the bottom and near the tank cover. When $T_{0}>T_{*}$ conditions for the development of instability where created almost immediately after the experiment started both near the bottom and near the cover. If $T_{0}<T_{*}$ conditions for developing instability where formed later. In that case, the delay of the instability appearance near the bottom was defined by the time of bottom heating to a temperature exceeding $T_{*}$ and it was not large. The time delay of instability near the cover was larger. It was defined by 
the time required for heating of the vertical walls and for lifting of heated water with a temperature of greater than $T_{*}$ to the cover.

Figure 2 shows the examples of dimensionless temperature dependences $T^{0}=T / T_{*}$ on dimensional time $t$ counted down from the start of the experiment. The sensor was located on the vertical axis of symmetry of the tank. The dependences are given for three values of the vertical coordinate $z$ and for three values of the initial water temperature $T_{0}$ in the tank. After a while, temperatures in all three examples acquired the same constant value $T_{a s} \approx 4.8{ }^{\circ} \mathrm{C}$. The time lag at which the temperature become constant depends on $T_{0}$. In the case of $T_{0}<4{ }^{\circ} \mathrm{C}$ this lag was equal to $2.5 \div 3$ hours and in the case of $T_{0}>4{ }^{\circ} \mathrm{C}$ it increased to 8 hours.

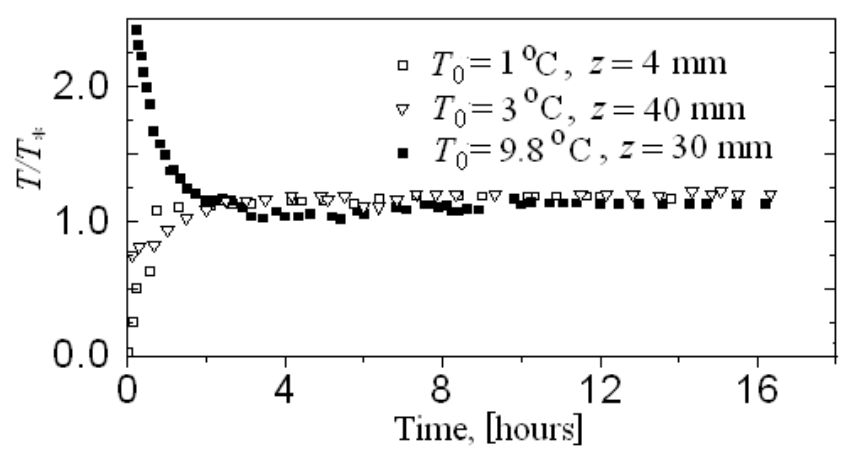

Figure 2. Temperature on the vertical axis of symmetry of the tank

Figure 3 shows the analogous dependences obtained with the sensors glued to the inner surfaces of the glass walls. One sensor was located in the middle of the tank bottom and two other ones were located in the middles of the side and end walls. The initial water temperature in this experiment was lower than $4{ }^{\circ} \mathrm{C}$. The steady state formed on vertical walls in approximately 3 hours. The temperature of water near the vertical walls was $0.8 \div 1.2{ }^{\circ} \mathrm{C}$ higher than that in the middle part of the tank (see Figure 2). The steady state at the bottom was formed in approximately 5 hours. The temperature of water near the bottom was a little less than near the vertical walls. It was almost equal to the temperature of water above (see Figure 2). It should be noted that the sensing element of the transducer was located at the distance of $1 \mathrm{~mm}$ from the bottom. Therefore, this result means only that the boundary layer at the bottom was thinner than $1 \mathrm{~mm}$ in the steady state.

Figure 4 shows the results of the measurements near the inner and outer surfaces of the left side wall. The sensors were located in the middle of the wall height. The steady state was formed within 2.5 hours. Temperature fluctuations took place in the air boundary layer on the side wall. They are due to air motions in the room out of the boundary layer. The difference of temperatures near the outer and inner surfaces of the side walls in the steady state was equal to $2.8{ }^{\circ} \mathrm{C}$ on the average. Almost the same drop of temperatures was on the end walls of the tank. The difference of temperatures between the outer and inner surfaces of the bottom was less then on the vertical walls. It was equal about $2.1{ }^{\circ} \mathrm{C}$. 


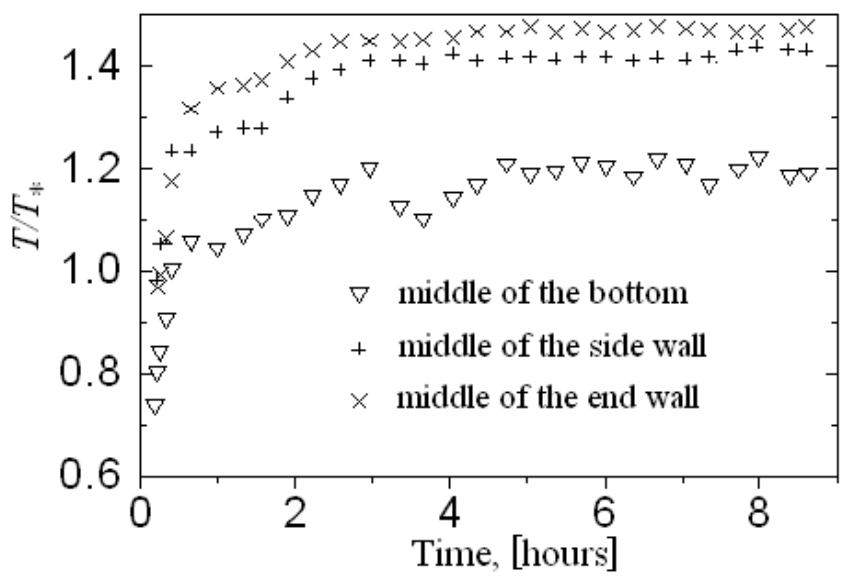

Figure 3. Temperature on the inner surfaces of the tank glass walls

$$
T_{\infty}=19.5 \pm 0.3{ }^{\circ} \mathrm{C}, \quad T_{0}=0.6{ }^{\circ} \mathrm{C}
$$

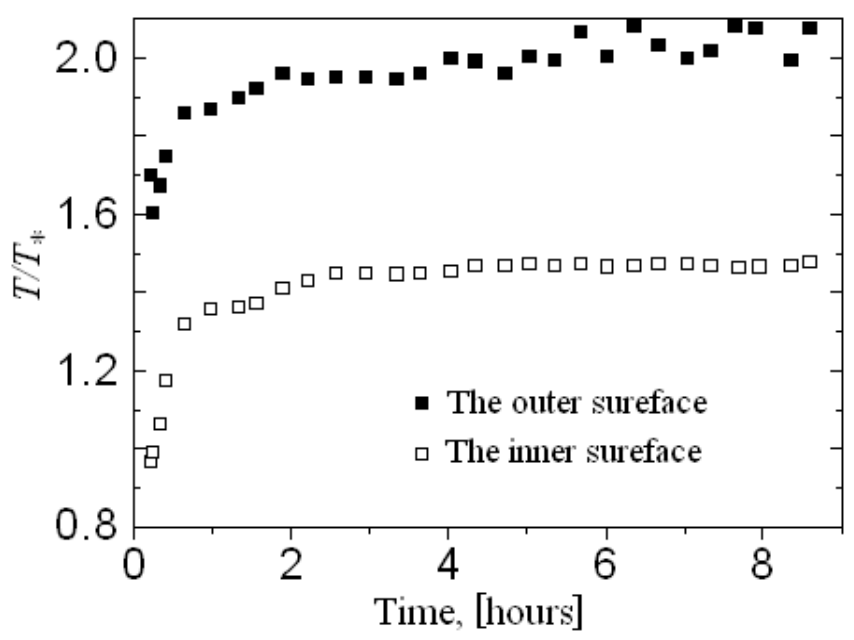

Figure 4. Temperature on the outer and inner surfaces of the tank side wall

$$
T_{\infty}=19.5 \pm 0.3{ }^{\circ} \mathrm{C}, T_{0}=0.6{ }^{\circ} \mathrm{C}
$$

Figure 5 shows the profiles $T^{0}(z / H)$ at the vertical axis of symmetry of the tank $(x=y=0)$ at two instants of time in the same experiment. The obtained data show that a thick layer of water with a constant temperature took place near the bottom. The temperature in this layer was about $4.8{ }^{\circ} \mathrm{C}$. The lower part of this layer was located almost at the bottom. Temperature fluctuations with a typical period of 10-20 sec took place near the upper boundary of this layer. The fluctuations were due to the fact that water sinking from the boundary layer on the cover occurred non-uniformly in time and space. As a result, the sensor interacted alternatively with warmer or colder water. 


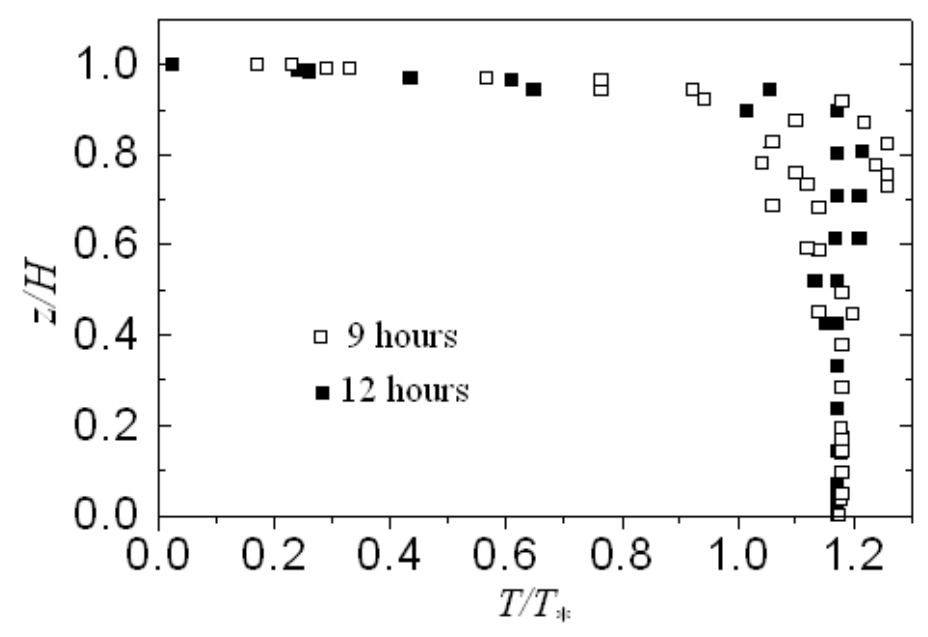

Figure 5. Temperature profiles at two instant of time

$$
T_{\infty}=19.5 \pm 0.3{ }^{\circ} \mathrm{C} ; \quad T_{0}=1{ }^{\circ} \mathrm{C}
$$

Laterally, the thick near-bottom layer with a constant temperature extended almost to the vertical walls. Figure 6 presents the example of vertical temperature profiles in the steady state at the axis of symmetry of the tank, and at the distance of $1.7 \mathrm{~cm}$ from the end wall and at the distance of $0.1 \mathrm{~cm}$ from this wall. At the distance of $1.7 \mathrm{~cm}$, temperature fluctuations are absent and the temperature in the vicinity of $z / H=0.9$ is a little more than at other values of $z / H$. This is due to the peculiarities of heat-exchange process in the corners between the side walls and the cover of the tank. In other respects, the temperature profile at the distance of $1.7 \mathrm{~cm}$ from the wall differs slightly from that at the axis of symmetry of the tank.

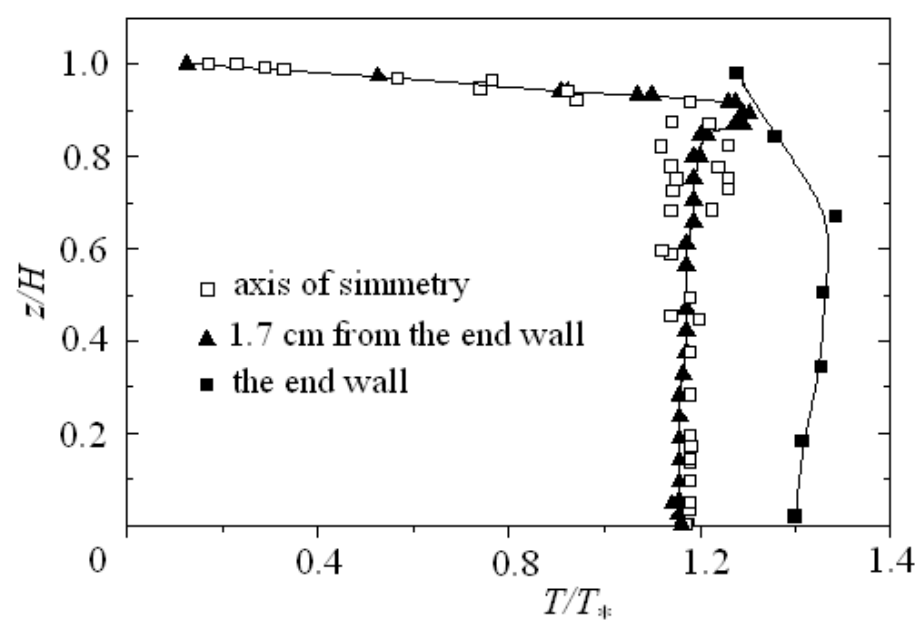

Figure 6. Temperature profiles at three verticals in the tank

$$
T_{\infty}=19.5 \pm 0.3{ }^{\circ} \mathrm{C} ; \quad T_{0}=1{ }^{\circ} \mathrm{C} ; t=9.5 \mathrm{~h} .
$$




\section{Macrothink}

Aquatic Science and Technology

ISSN 2168-9148 2013, Vol. 1, No. 1

Figure 7 presents typical patterns of distribution of ink-colored water after a long time from the start of the experiment. The initial water temperature was equal to $6.5{ }^{\circ} \mathrm{C}$ in this experiment. The ink solution whose density exceeded the initial water density about $0.001 \%$ was released on the bottom through a brass tube at the point located at the distance of $8 \mathrm{~cm}$ from the left end wall of the tank. The tube and the holder of the temperature sensor can be seen in Figure 7. The caption for Figure 7 contains the time values $t$ from the start of the experiment at which the images are obtained. The ink solution was introduced in time $t_{*}=4.5$ hours when the heat-exchange process was near to the steady state.

(a)

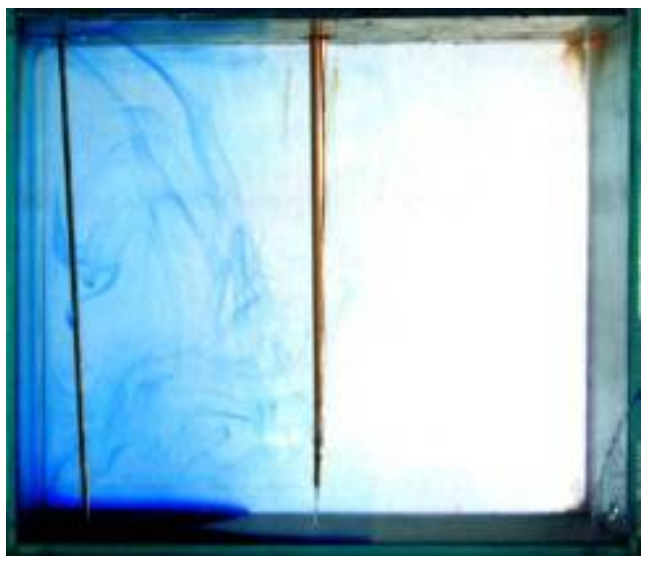

(b)

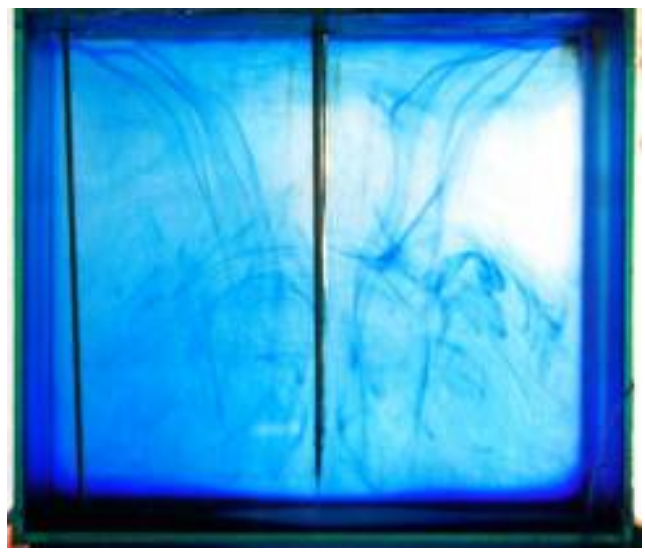

(c)

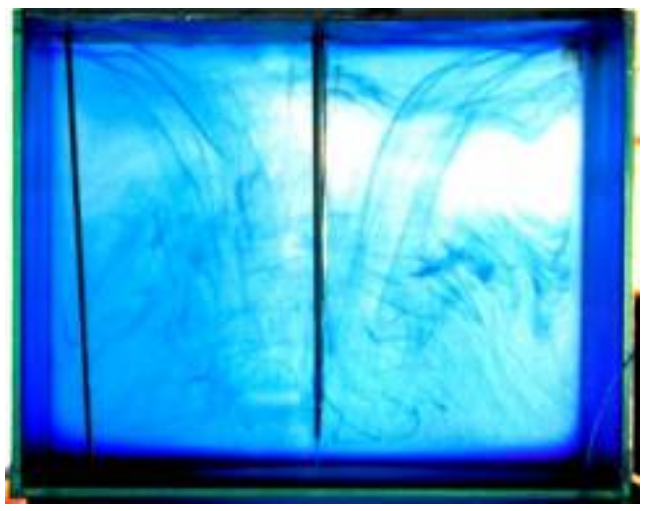

Figure 7. Evolution of ink-colored water

$T_{\infty}=19.5 \pm 0.3{ }^{\circ} \mathrm{C}, T_{0}=6.5^{\circ} \mathrm{C} ;(\mathrm{a})-t=4.7 \mathrm{~h} .,(\mathrm{b})-t=6.7 \mathrm{~h} .,(\mathrm{c})-t=8 \mathrm{~h} . ; t_{*}=4.5 \mathrm{~h}$.

The colored water spread along the bottom very slowly and was considerably faster entrained into the upward flow in the boundary layers on the vertical walls. At the time instant corresponding to the image in Figure 7(a), the ink solution spreading along the bottom has not reached the tank middle yet whereas the ink solution rising along the walls and then sinking out the boundary layer on the cover has already colored the left half of the tank. At later times corresponding to the images in Figure 7(b) and Figure 7(c), ink colored both the 


\section{Macrothink}

boundary layer at the right wall and water that is far from the walls in the right part of the tank.

The propagation speeds of the selected fronts of the colored water were determined by video filming. These speeds were identified as the velocities of the movement of clean water what is acceptable at small values of the velocities. At the steady state of heat exchange, the speeds were so small that the pattern of the ink distribution looked frozen [see Figure 7(b) and Figure 7(c)]. However, very slow water sinking from the upper layer continued at the steady stage as well.

The patterns of colored water distributions at non-stationary stages of the heat-exchange process are presented in Figure 8 and Figure 9. The illustrations given in Figure 8 were obtained with the help of the visualization by the potassium permanganate solution. The initial water temperature in the tank was higher than $4{ }^{\circ} \mathrm{C}$. The solution was injected in the form of a horizontal round jet into the boundary layer on the cover with a very small velocity. A small amount of the salt $\mathrm{NaCl}$ was preliminary diluted in the tank so that the initial density of the colored water was less than the density of the non-colored water by $0.001 \%$. The jet was started through $t_{*}=6.5$ minutes after the experiment started. The colored water accumulated at first under the cover during about 5 minutes. Then a part of the colored water acquired almost the maximal density and sank with velocity equaled approximately 0.15 $\mathrm{cm} / \mathrm{sec}$. The discrete structures called "the fingers" (Turner, 1973) were formed at the initial stage of sinking.

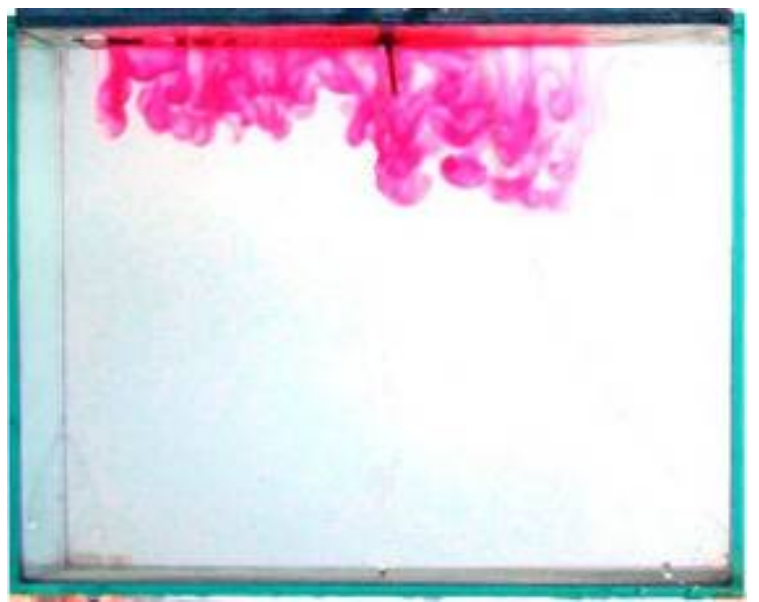

Figure 8 . Initial stage of instability near the tank cover

$$
T_{\infty}=19.5 \pm 0.3{ }^{\mathrm{o}} \mathrm{C}, T_{0}=9.8{ }^{\mathrm{o}} \mathrm{C} ; t=12.5 \text { minutes, } t_{*}=6.5 \text { minutes }
$$

The illustrations obtained with the use of uranine are given in Figure 9. !! Colored water issued through a hole in the cover middle in the form of a vertical jet $1 \mathrm{~cm}$ in diameter and with the velocity about $0.05 \mathrm{~cm} / \mathrm{sec}$. The initial density of colored water exceeded the initial water density in the tank by $0.0005 \%$. The jet start time was equal to $t_{*}=20$ minutes. Owing 


\section{Macrothink

to the influence of a weak negative buoyancy force and an initial momentum directed downwards, the jet sank and the colored water accumulated mainly near the bottom. Uranine colored also some layer near the cover owing to the fact that the part of colored solution which was in contact with the cover acquired a temperature close to $0{ }^{\circ} \mathrm{C}$ and turned out to be lighter than water with the temperature of $4{ }^{\circ} \mathrm{C}$.

The initial temperature $T_{0}$ in the example considered was equal to the asymptotic temperature $T_{a s} \approx 4.8{ }^{\circ} \mathrm{C}$. In this case, the convective instability near the bottom played an important role in forming the layer with constant temperature. Warmer water rose to a limited height then it acquired almost the maximal density and sank. In meteorology, the process of alternate rising and sinking of air is characterized as "penetrative convection". It is possible to see the mushroom-like structure and the thin jet in Figure 9. Forms of these structures indicate that horizontal velocities in the tank out of the bottom boundary layer were small.

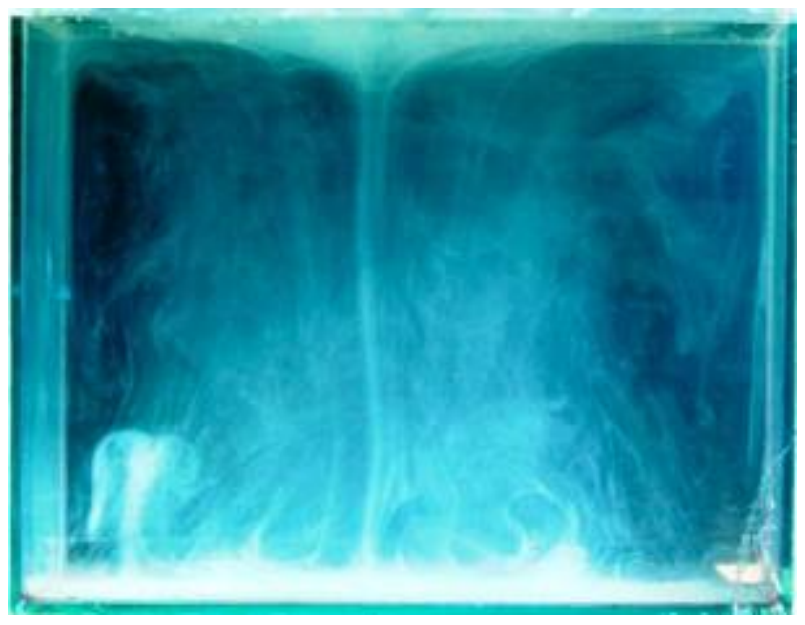

Figure 9. Convective instability near the tank bottom

$$
T_{\infty}=19.8{ }^{\circ} \mathrm{C}, T_{0}=4.4{ }^{\circ} \mathrm{C} ; t=0.75 \mathrm{~h} ., t_{*}=0.3 \mathrm{~h}
$$

\section{Discussion of Results}

The experiments showed that a sufficiently thick steady layer of water with a constant temperature was formed in the tank. This is the result of sinking of water with the almost maximal density from above and lifting of warm water from below. The non-monotonic dependence of the water density on temperature restricts both sinking and lifting. Lifting from the bottom was suppressed especially strongly so the steady near-bottom layer joined almost to the bottom. Heated water from a very thin boundary layer at the bottom was displaced in horizontal directions and than it was entrained into the boundary layers on the vertical walls. A relatively thick steady layer with almost linear mean distribution of density was formed near the cover. The constant temperature in the near-bottom layer was a little more $T_{*}$. Therefore, weak convective instability at the boundary between the upper and 
lower layers persisted even in the steady state of heat exchange. As a result, a part of water from the upper layer constantly sank.

The total heat intensity inflowing from air to water in the steady state was approximately equal to 77 watt in the examples presented in Figures 4-6. This evaluation was obtained as the results of temperature measurements on the outer and inner surfaces of the tank glass walls (see Figure 4). In the steady state, that heat was removed from the tank through its cover with the same intensity. The main heat was transferred to the cover by the convection in the boundary layers on the vertical walls. A part of the heat was transferred to the cover by the molecular diffusion directly from the near-bottom layer with constant temperature. The intensity of that part of the total transfer was evaluated according to the experimental data presented in Figure 5 and Figure 6. It was about 7.2 watt i.e. it was less than $10 \%$ of the total intensity.

The temperature distributions along the depth shown in Figure 5 have some likeness with those in Lake Baikal. The detailed information about the temperature regime of this lake is contained, for example, in the monograph (Shimarayev, 1977). The profiles of temperature in the middle part of Lake Baikal in two winter and two summer months in 1973-74 years show in Figure 10. The tabular data (Shimarayev, 1977) are used for the profiles.

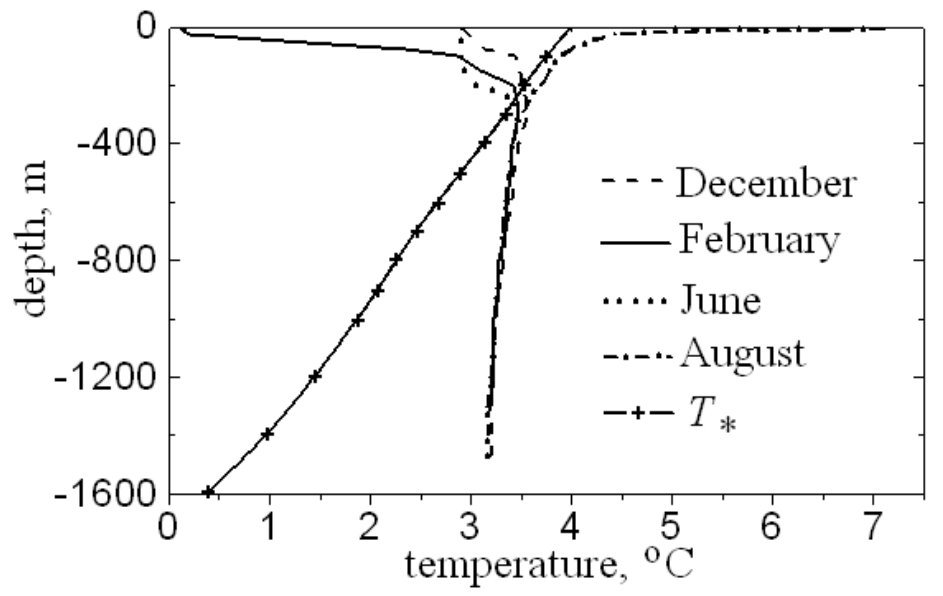

Figure 10. Vertical distributions of temperature in the middle part of Lake Baikal

(Shimarayev, 1977)

It is necessary to note that the conditions of heat exchange in Lake Baikal considerably differ from the conditions in the present experiment. In the experiment, the temperature on the upper boundary was constant and equal to $0.1{ }^{\circ} \mathrm{C}$. In Lake Baikal, seasonal temperature changes take place on the upper boundary. In the experiment, the convective transfer in the boundary layers on the tank walls played defining role. The length and width of Lake Baikal considerably exceed its depth so such mechanism of the vertical heat transfer is absent. Coriolis's force and horizontal gradients of pressure and temperature are essential for Lake Baikal. The distribution of the water density along the depth of a deep lake depends on pressure. Particularly, pressure effects the value of the temperature $T_{*}$ at which water has 
the maximal density. The density maximum is shifted to lower temperatures with pressure increasing. The dependence of the value $T_{*}$ on the depth for Lake Baikal is presented in Figure 10. The empirical formula (Chen \& Millero, 1986) was used for this dependence.

Nevertheless, a thick near-bottom layer with an almost constant water temperature also exists in Lake Baikal independent of season. Formation of this layer is determined by other processes than in the laboratory experiment. However, the steady state of this layer is maintained due to anomalous thermodynamic properties of water (Shimarayev, 1977).

The nonlinear and non-monotonic dependence of the density of water on temperature complicates strict mathematical and numerical modeling. Additional difficulties of modeling are connected with that the processes considered are unstable. At numerical computations of water movements after loss of stability, various approximate mathematical models are used (Musman, 1968; Botcharov \& Ovtchinnikova, 1996; Tong, 2004). The obtained experimental data are useful to check of results of such computations.

\section{Conclusions}

A steady two-layer distribution of the mean temperature of water over the depth with a thick lower layer of constant temperature and a thinner upper layer with almost linear change of a temperature on the depth is realized in the laboratory experiment. It is shown that non-monotonic dependence of the water density on temperature generates convective instability and considerably influences formation of such steady state. Heating of water from below along with cooling from above is an important factor also.

Limited dimensions of a tank essentially affect the convection especially in anomalous conditions. Dynamic and thermal boundary layers on the tank walls can have defining meaning for heat exchange processes in this case. It is essential to heat exchange processes in technical devices.

\section{Acknowledgement}

This work was supported by the Russian Foundation for Basic Research (Grant No. 10-01-00006) and Integration projects of the Siberian Division of the Russian Academy of Sciences No. 38 and No. 2.133.

\section{References}

Adrian, R. J. (1975). Turbulent convection in water over ice. Journal of Fluid Mechanics, 69(4), 753-781. http://dx.doi.org/10.1017/S002211207500167X

Botcharov, O. B., \& Ovtchinnikova, N. E. (1996). Numerical modeling of thermal bar in lake Baikal. The journal "Computational Technologies", 1(3), 21-28. http://www.ict.nsc.ru/jct/getfile.php?id=19 (Full text PDF in Russian); http://www-sbras.nsc.ru/mathpub/comp-tech/eng/ (Abstract in English).

Bukreev, V. I. (2011). Plunging current caused by non-monotonous water density dependence on temperature. Oceanology, 51(4), 574-581. http://dx.doi.org/10.1134/S0001437011040059 
Bukreev, V. I., \& Gavrilov, N. V. (2010). Instability of the thermal bar formed in a gravity Current. Doklady Earth Sciences, 430(1), 151-154. http://dx.doi.org/10.1134/S1028334X10010332

Chen, C. T., \& Millero, F. J. (1986). Precise thermodynamic properties for natural water covering only the limnological range. Limnol. Oceanogr., 31(3), 657-662. http://www.aslo.org/lo/toc/vol_31/issue_3/0657

Chubarenko, I. P., \& Demchenko, N. Yu. (2008). Laboratory modeling of the structure of a thermal bar and related circulation in a basin with a sloping bottom. Oceanology, 48(3), 356-379. http://dx.doi.org/10.1134/S0001437008030041

Forel, F. A. (1904). Le Leman, monographie llimnologoque. Lausanne: Librairie de l'Université. http://archive.org/details/lelmanmonograp03fore

Holland, P. R., \& Kay, A. (2003). A review of the physics and ecological implications of the thermal bar circulation. Limnologica - Ecology and Management of Inland Waters, 33(3), 153-162. http://dx.doi.org/10.1016/S0075-9511(03)80011-7

Imberger, \& Hamblin, P. F. (1982). Dynamics of lakes, reservoirs, and cooling ponds. Ann. Rev. Fluid Mech., 14, 153-187. http://dx.doi.org/10.1146/annurev.fl.14.010182.001101

Musman, S. (1968). Penetrative convection. J. Fluid Mech., 31(2). 343-360. http://dx.doi.org/10.1017/S0022112068000194

Shimarayev, M. N. (1977). Elements of a thermal regime of Lake Baikal. Nauka, Novosibirsk. (in Russian)

Singh, B., \& Shah, C. R. (1971). Plunging Phenomena of Density Currents in Reservoirs. La Houille Blanche, 26(1), 59-64. http://dx.doi.org/10.1051/lhb/1971005

Tichomirov, A. I. (1983). Thermal regime of large lakes. Nauka, Leningrad. (in Russian)

Tong, W. (2004). Aspect ratio effect on natural convection in water near its density maximum temperature. Int. J. Heat and Fluid Flow, 20(6), 624-633. http://dx.doi.org/10.1016/S0142-727X(99)00027-2

Townsend, A. A. (1964). Natural convection in water over an ice surface. Q. J. Roy Meteorol. Soc., 90(385), 248-259. http://dx.doi.org/10.1002/qj.49709038503 (abstract)

Turner, J. S. (1973). Buoyancy effects in fluids. Cambridge Univ. Press, Cambridge.

Zilitinkevch, S. S., Kreiman, K. D., \& Terzhevik, A. Yu. (1992). The thermal bar. J. Fluid Mech., 236, 27-42. http://dx.doi.org/10.1017/S0022112092001320

\section{Glossary}

$H-$ tank height

h. - abbreviation of hour

$t$ - time from the beginning of the experiment 
$t_{*}$ - time from the beginning of the dye input

$T$ - temperature

$T_{*}$ - temperature at which water has maximal density

$T_{0}-$ initial temperature of water in the tank

$T_{\infty}$ - initial temperature of air in the laboratory

$T_{a s}$ - asymptotic temperature of the water in the lower layer

$T^{0}=T / T_{*}-$ dimensionless temperature

$x$ - longitudinal coordinate

$y$ - transverse coordinate

$z$ - vertical coordinate

\section{Copyright Disclaimer}

Copyright reserved by the author(s).

This article is an open-access article distributed under the terms and conditions of the Creative Commons Attribution license (http://creativecommons.org/licenses/by/3.0/). 